\title{
Prison smoking bans in the United States: current policy, impact and obstacle
}

\author{
Jianrong Zhang \\ George Warren Brown School, Washington University in St. Louis, St. Louis, MO, USA \\ Correspondence to: Dr. Jianrong Zhang, MD, MPH Candidate. George Warren Brown School, Washington University in St. Louis, One Brookings \\ Drive, Campus Box 1196, St. Louis, MO 63130, USA. Email: Jianrong.zhang@wustl.edu.
}

\begin{abstract}
Smoking is the leading preventable risk factor of mortality in the United States. The threat of smoking is severer in prisons. Compared with the general US population, prisoners have a higher prevalence of smoking, as well as a higher smoking-related mortality. Nowadays, smoking bans have been enacted in 49 states' federal correctional facilities, including 100\% smoke-free and tobacco-free indoors and outdoors on all grounds (20 states), 100\% smoke-free indoors and outdoors on all grounds (1 state), 100\% smokefree and tobacco-free indoors (16 states), and 100\% smoke-free indoors (12 states). After implementation, a mortality reduction has been achieved, especially for cancers and respiratory diseases. In addition, a more comprehensive restriction (e.g., smoking and tobacco bans indoors and outdoors) and a longer implementation contribute to a higher reduction of mortality. However, some obstacles should not be ignored, such as the high relapse rate of smoking after release, existence of smoking in smoking-free prisons, nicotine dependence and nicotine withdrawal symptoms led by the bans, potentially high prevalence of mental illnesses among prisoners who also smoke, etc. Given the impact and obstacle of the current smoking bans, the author recommends that: (I) smoking bans should be kept enacting according to the mortality reduction after implementation; (II) more restrictive bans should be considered across the U.S. States, such as smoking-free insides and outsides on the ground; (III) further efforts should be made for reducing the high relapse rate of smoking after release; (IV) other implementations combining with smoking bans should be considered for smoking inmates with mental illnesses.
\end{abstract}

Keywords: Smoking bans; prison; the United States

Received: 18 April 2018; Accepted: 28 April 2018; Published: 06 May 2018.

doi: 10.21037/jhmhp.2018.04.06

View this article at: http://dx.doi.org/10.21037/jhmhp.2018.04.06

\section{Introduction}

Smoking is the leading preventable risk factor of mortality in the United States, with an estimated 467,000 deaths each year, nearly one in five deaths in the US adults (females: 219,000 deaths; males: 248,000 deaths) (1). According to the latest update, in 2014-2015 the prevalence of the US adults who ever used tobacco products ranged from $27.0 \%$ (Utah) to $55.4 \%$ (Wyoming); the prevalence of the current use of tobacco products ranged from $10.2 \%$ (California) to $27.7 \%$ (Wyoming) (2). Smoking is a threat not just for smokers themselves, but also for the people who are around them due to the second-hand smoking exposure (3).

The smoking situation among prisoners is severer. In prisons, the prevalence of smoking is nearly $70 \%$, far higher than the prevalence in the US general population (4). Compared with the general population, the incarcerated people have higher risks for a number of smoking-related chronic diseases (5). Also, they have a higher mortality $(6,7)$. According to the last updated statistics, the ageadjusted, smoking-related mortality among inmates was 360 per 100,000 in the United States (general US population: 248 per 100,000$)(8)$. In addition, a three times higher mortality rate was found in inmates with mental illness (9), 
the disease associated with smoking (10).

\section{Current policy}

For smoking in prison, related controls have been implemented. From 2001 to 2011, the number of states with any smoking bans increased from 25 to 48 (8). Nowadays, smoking bans have been enacted in 49 states' federal correctional facilities (11). Specifically, these bans include four types: $100 \%$ smoke-free and tobacco-free indoors and outdoors on all grounds (20 states), 100\% smoke-free indoors and outdoors on all grounds (1 state), 100\% smokefree and tobacco-free indoors (16 states), and 100\% smokefree indoors (12 states).

\section{Impact}

The effect of the smoking bans has been evaluated, according to the data reported by the Bureau of Justice Statistics (8). Compared to the years without the smoking bans, the smoking-related mortality had a nine-percent reduction during the years with the smoking bans (mortality rate before $v s$. after the bans: $128.9 v s .110 .4$ per $100,000)$. In addition, the mortality reduction was more effective when the smoking bans were implemented longer ( $0-4$ years: $4 \% ; 4-9$ years: $7 \% ; \geq 9$ years: $11 \%)$. Furthermore, a comprehensive restriction, including smoking and tobacco bans indoors and outdoors, contributed to a lower smoking-related mortality. After nine or over nine years' implementation, the ban achieved a mortality reduction of $19 \%$ and $34 \%$, respectively, for cancers and pulmonary diseases (8).

The effect of the smoking ban on mortality reduction is also effective for the inmates with mental illnesses. Tobacco usage has been significantly reduced and eliminated in the facilities of the New Jersey Department of Corrections from 2005 to 2014 (9). In this period, the mortality reduction among the inmates with mental illnesses was significantly correlated with the reduction of the tobacco products. The ban achieved $48 \%$ of the mortality reduction after implementation (mortality rate before $v s$. after the ban: 676 vs. 353 per 100,000 population) (9).

In addition to the mortality reduction, the smoking bans also improve the air quality in prisons (12-15). This could reduce the exposure to the second-hand smoking, beneficial not just for the inmates (including smokers and non-smokers), but also for the prison officers and other staff. Theoretically, the bans may eliminate the initiation of smoking among originally non-smoking inmates.

\section{Obstacles}

For the smoking bans, obstacles should not be ignored. First, the relapse rate of smoking is high after release. Studies showed that the prevalence of current smokers was more than $73 \%$ among former inmates from prisons with smoking bans (16-18). Second, even though the correctional facilities have enacted the smoking bans, some inmates are still able to smoke. According to one study investigating 146 former prisoners who had to quit smoking due to the smoking bans, $12 \%$ of them reported they smoked in prison (17). Third, the smoking bans may lead to nicotine dependence and nicotine withdrawal symptoms (18). According to the above obstacles, the smoking bans may not successfully achieve a long-term smoking cessation.

Fourth, quitting smoking may be challenging in prisoners with a mental illness. According to the newest statistics, the smoking prevalence among individuals with severe mental illness $(35.8 \%)$ is over two times higher than in the US general population (15.5\%) (10). In addition, compared to the general population, the prevalence of mental illnesses among prisoners is higher (19). In the facilitates of the Iowa Department of Corrections, a study found $48 \%$ of 8,574 prisoners had mental illness; among them, $29 \%$ were diagnosed with a serious mental illness (20). Given the above data, the author assumes that the prevalence of smoking among inmates who have mental illness is higher than the prevalence of smoking among the general population in prisons. With mental illness, quitting smoking may be challenging.

\section{Recommendation}

(I) Smoking bans should be kept enacting in prisons. This recommendation is supported by a population-level study in the United States. After implementation, smoking bans achieved a $9 \%$ mortality reduction (8). Also, a longer implementation can achieve a higher mortality reduction. For example, a 9- or over 9-year implementation achieved a mortality reduction of $11 \%$ from all smoking related causes, $19 \%$ from cancers, and $34 \%$ from pulmonary diseases (8).

(II) More restrictive bans, such as smoking-free insides and outsides on the ground, deserve a nationwide implementation across the U.S. States. This 
recommendation is also supported by the same study: with a more comprehensive smoking restriction, a higher rate of mortality reduction was achieved (8).

(III) Further efforts should be made for reducing the high relapse rate (over $73 \%$ ) of smoking after release (16-18). A smoking cessation program based on pharmacological and behavioral strategies, as well as related postrelease services could be considered.

(IV) Due to a high relation of smoking and mental illness (10), as well as the high prevalence rate (nearly $30 \%$ ) of severe mental illness in prisons (20), other implementations combining with smoking bans should be considered, such as medical services for mental illnesses.

\section{Acknowledgments}

The author thanks Ms. Carolyn Smith (Senior Tutor, The Writing Center at Washington University in St. Louis), Dr. Christine Ekenga (Assistant Professor, Brown School at Washington University in St. Louis), and Mr. Gary Parker (Associate Dean of External Affairs, Director of the Clark Fox Policy Institute, Brown School at Washington University in St. Louis) for providing suggestions on manuscript revision. The idea of the present article comes from a policy debate by the author and Ms. Caroline Wentworth (MD/MPH Candidate, Washington University School of Medicine, Brown School at Washington University in St. Louis) in a course "Foundations of Public Health: Health Administration and Policy" lectured by Prof. Linda L. Raclin (Senior Lecture, Brown School at Washington University in St. Louis). Also, this article has been presented in a course "Foundations of Public Health: Environmental Health" lectured by Prof. Ekenga.

Funding: None.

\section{Footnote}

Provenance and Peer Review: This article was a standard submission to the journal. The article did not undergo external peer review.

Conflicts of Interest: The author has completed the ICMJE uniform disclosure form (available at http://dx.doi. org/10.21037/jhmhp.2018.04.06). The author has no conflicts of interest to declare.

Etbical Statement: The author is accountable for all aspects of the work in ensuring that questions related to the accuracy or integrity of any part of the work are appropriately investigated and resolved.

Open Access Statement: This is an Open Access article distributed in accordance with the Creative Commons Attribution-NonCommercial-NoDerivs 4.0 International License (CC BY-NC-ND 4.0), which permits the noncommercial replication and distribution of the article with the strict proviso that no changes or edits are made and the original work is properly cited (including links to both the formal publication through the relevant DOI and the license). See: https://creativecommons.org/licenses/by-nc-nd/4.0/.

\section{References}

1. Danaei G, Ding EL, Mozaffarian D, et al. The preventable causes of death in the United States: comparative risk assessment of dietary, lifestyle, and metabolic risk factors. PLoS Med 2009;6:e1000058.

2. Odani S, Armour BS, Graffunder CM, et al. State-Specific Prevalence of Tobacco Product Use Among Adults United States, 2014-2015. MMWR Morb Mortal Wkly Rep 2018;67:97-102.

3. Oberg M, Jaakkola MS, Woodward A, et al. Worldwide burden of disease from exposure to second-hand smoke: a retrospective analysis of data from 192 countries. Lancet 2011;377:139-46.

4. Lincoln T, Tuthill RW, Roberts CA, et al. Resumption of smoking after release from a tobacco-free correctional facility. J Correct Health Care 2009;15:190-6.

5. Binswanger IA, Krueger PM, Steiner JF. Prevalence of chronic medical conditions among jail and prison inmates in the USA compared with the general population. J Epidemiol Community Health 2009;63:912-9.

6. Binswanger IA, Blatchford PJ, Mueller SR, et al. Mortality after prison release: opioid overdose and other causes of death, risk factors, and time trends from 1999 to 2009. Ann Intern Med 2013;159:592-600.

7. Binswanger IA, Stern MF, Deyo RA, et al. Release from prison--a high risk of death for former inmates. $\mathrm{N}$ Engl J Med. 2007;356:157-65. Erratum in: N Engl J Med 2007;356:536.

8. Binswanger IA, Carson EA, Krueger PM, et al. Prison tobacco control policies and deaths from smoking in United States prisons: population based retrospective analysis. BMJ 2014;349:g4542.

9. Dickert J, Williams JM, Reeves R, et al. Decreased 
Mortality Rates of Inmates With Mental Illness After a Tobacco-Free Prison Policy. Psychiatr Serv 2015;66:975-9.

10. Jamal A, Phillips E, Gentzke AS, et al. Current Cigarette Smoking Among Adults - United States, 2016. MMWR Morb Mortal Wkly Rep 2018;67:53-59.

11. $100 \%$ Smokefree and Tobacco-Free Correctional Facilities. American NonSmokers' Rights Foundation. 2018 Apr 1. Available online: http://no-smoke.org/wpcontent/uploads/pdf/100smokefreeprisons.pdf (Retrieved 14 Apr 2018).

12. Ritter C, Huynh CK, Etter JF, et al. Exposure to tobacco smoke before and after a partial smoking ban in prison: indoor air quality measures. Tob Control 2012;21:488-91.

13. Thornley S, Dirks KN, Edwards R, et al. Indoor air pollution levels were halved as a result of a national tobacco ban in a New Zealand prison. Nicotine Tob Res 2013;15:343-7.

14. Kennedy SM, Davis SP, Thorne SL. Smoke-Free Policies in U.S. Prisons and Jails: A Review of the Literature. Nicotine Tob Res 2015;17:629-635.

15. Hammond SK, Emmons KM. Inmate exposure to

doi: 10.21037/jhmhp.2018.04.06

Cite this article as: Zhang J. Prison smoking bans in the United States: current policy, impact and obstacle. J Hosp Manag Health Policy 2018;2:20. secondhand smoke in correctional facilities and the impact of smoking restrictions. J Expo Anal Environ Epidemiol 2005;15:205-11.

16. Howell BA, Guydish J, Kral AH, et al. Prevalence and factors associated with smoking tobacco among men recently released from prison in California: A crosssectional study. Addict Behav 2015;50:157-60.

17. Frank MR, Blumhagen R, Weitzenkamp D, et al. Tobacco Use Among People Who Have Been in Prison: Relapse and Factors Associated with Trying to Quit. J Smok Cessat 2017;12:76-85.

18. Cropsey KL, Kristeller JL. The effects of a prison smoking ban on smoking behavior and withdrawal symptoms. Addict Behav 2005;30:589-94.

19. Fazel S, Hayes AJ, Bartellas K, et al. Mental health of prisoners: prevalence, adverse outcomes, and interventions. Lancet Psychiatry 2016;3:871-81.

20. Al-Rousan T, Rubenstein L, Sieleni B, et al. Inside the nation's largest mental health institution: a prevalence study in a state prison system. BMC Public Health 2017;17:342. 